\title{
A WESTERN TROPICAL ATLANTIC EXPERIMENT (WESTRAX)
}

By Wendell S. Brown, William E. Johns, Kevin D. Leaman, Julian P. McCreary, Robert L. Molinari, Phillip L. Richardson and Claus Rooth

$\mathrm{R}$

ECENTLY, a group of researchers from the U.S. and the broader international community have developed coordinated plans for observational and modeling work in the western tropical Atlantic. The overall research program is referred to as WESTRAX, for Western Tropical Atlantic Experiment. This article summarizes the research plans of the various participants and the scientific issues that have motivated the studies.

\section{Background}

Ocean heat flux is a significant component of the global energy balance. Vonder Haar and Oort (1973) found that, on a global average, the oceans between the equator and $\sim 30^{\circ} \mathrm{N}$ transport more than half the heat required to balance the energy loss at more poleward latitudes. At subtropical latitudes in the North Atlantic (where the ocean heat flux is a maximum), western boundary currents represent an important component in the global heat budget (Bryden and Hall, 1980). Global-scale thermohaline circulation is believed to play a central role in the net northward interhemispheric transport of mass and heat in the Atlantic Ocean (Broecker et al., 1985; Atlantic Climate Change Working Group, 1990). The notion of a global thermohaline "conveyor belt" involves warm upper-ocean transport from the Indian and Pacific Oceans moving northward through the Atlantic and a southward return of colder deep flow from the subpolar regions in the North Atlantic.

Important components of the global thermohaline conveyor belt are seen in the tropical Atlantic. The cross-equatorial transport of upper

W.S. Brown, Ocean Process Analysis Laboratory, University of New Hampshire, Durham, NH 03824 USA. W.E. Johns, K.D. Leaman and C. Rooth, RSMAS/MPO, University of Miami, Miami. FL 33149 USA. E.J. Katz. Lamont-Doherty Geological Observatory, Columbia University, Palisades, NY 10964 USA. J.P. McCreary, Nova University. Dania. FL 33004 USA. R.L. Molinari, Environmental Research Laboratories, AOML/NOAA, Miami, FL 33149 USA. P.L. Richardson, Woods Hole Oceanographic Institution, Woods Hole, MA 02543 USA. tropical Atlantic waters is comparable with the total rate of equatorial upwelling driven by the tropical wind systems. Thus, it appears that the deep and shallow parts of this meridional overturning system may be linked in the tropics. There is reason to believe that an improved understanding of these so-called conveyor-belt dynamics will help explain observed correlations between African and Brazilian drought cycles and ocean surface-temperature asymmetries in the Atlantic. It is hypothesized that changes in the meridional overturning rate induce climatically important changes in the surface ocean temperature anomalies.

What is the role of the tropical Atlantic in the northward interhemispheric heat transport in the Atlantic basin? To answer this question, it will be important to determine how much water is transported across the equator at different depths within the western-boundary current system and what fraction of this water is carried poleward into the subtropical basins of the North and South Atlantic. Answering this question requires a more complete understanding of the structure of western-boundary currents in the tropical Atlantic and their coupling to the interior circulation. A growing body of observations suggests that, at the surface, the northern-hemisphere summer and fall circulation in the western tropical Atlantic is dominated by the retroflection of an intense western-boundary current known as the north Brazil current (NBC). During this time. the upper layer of the NBC, which transports from 30 to 50 Sverdrups, feeds the north equatorial countercurrent (NECC). The lower layers of the NBC within and just below the thermocline also retroflect (Metcalf and Stalcup, 1967), but apparently at different locations, to feed the equatorial undercurrent and the subsurface branches of the NECC - more permanent features of the circulation. This layered structure of the NBC appears to be connected in some way to the presence of two quasipermanent eddies adjacent to the western boundary near $4^{\circ} \mathrm{N}$ and $8^{\circ} \mathrm{N}$, commonly referred to as the Amazon and Demerara Eddies, respectively. These complex upper-level currents and underlying flows of
Important components of the global thermohaline conveyor belt are seen in the tropical Atlantic. 


\section{These complex}

upper-level currents

and underlying flows

play a central role

in the net northward

heat transport in the

Atlantic
Antarctic intermediate water, Antarctic bottom water, and North Atlantic deep water are believed to play a central role in the net northward heat transport in the Atlantic.

Several of the earliest observational programs [such as the Equatorial Atlantic Program (EQUALANT), 1963-1964] addressed some of these questions concerning variability in the interior tropical oceans. The Atlantic Tropical Experiment (summer and fall 1974) of the Global Atmospheric Research Program marked the beginning of modern intensive studies of tropical ocean dynamics in the Atlantic. Studies on the response of the tropical Atlantic to transient wind forcing ensued. Notable efforts include the Seasonal Response of the Equatorial Atlantic (SEQUAL) and the Français Ocean et Climat dans l'Atlantique Equatorial (FOCAL) complementary U.S. and French observational programs, during 1983-1984. In addition, the National Oceanic and Atmospheric Administration (NOAA), together with the Geophysical Fluid Dynamics Laboratory, developed a detailed numerical model for the basin-wide dynamic response to observed winds. Spanning this whole period has been the development of analytical and simplified numerical models aimed at understanding the physics of the wind-forced variability in the equatorial ocean on seasonal to interannual time scales. These efforts have contributed significantly to the development of models for El Nino dynamics in the Pacific.

The relatively few observations that have been made in the western tropical Atlantic have been used primarily to describe its large annual signal. Hydrography indicates that the most intense cir- culation and largest transports occur during the northern-hemisphere summer when the NBC retroflects and feeds the NECC (Fig. 1). The leastintense circulation and smallest transports occur during the northern-hemisphere winter when a significant portion of the NBC is believed to continue along the South American coast into the Caribbean (Johns and Molinari, 1989). A quantitative description is not yet available of the annual cycle for the upper ocean transport of either the NBC or the Amazon and Demerara Eddies, around which the NBC retroflects at times. In fact, recently analyzed satellite images of ocean-surface color (Muller-Karger et al., 1988) suggest that the Demerara Eddy is not even a steady feature. The work of Johns et al. (1990) suggests that the NBC retroflection sheds eddies, which move northwestward along the South American coast. At thermocline and subthermocline depths, indirect evidence indicates an annual modulation in the intensity of the Amazon Eddy and the subsurface branch of the NECC just to the east. The relationships between the boundary flows, eddies, and zonal currents remain essentially undefined, however.

Models ranging in dynamical complexity from simple analytical models (Csanady, 1985; Weisberg and Tang, 1985) to comprehensive general circulation models (GCMs) have been applied to the region. The numerical modeling studies of Philander and Pacanowski (1986) suggest that the surface currents of the western tropical Atlantic play an important role in ocean heat flux in the region. In particular, when the model NBC retroflects in the summer, northward heat flux is a

\section{NORTH BRAZIL CURRENT-WESTERN NECC (FALL)}

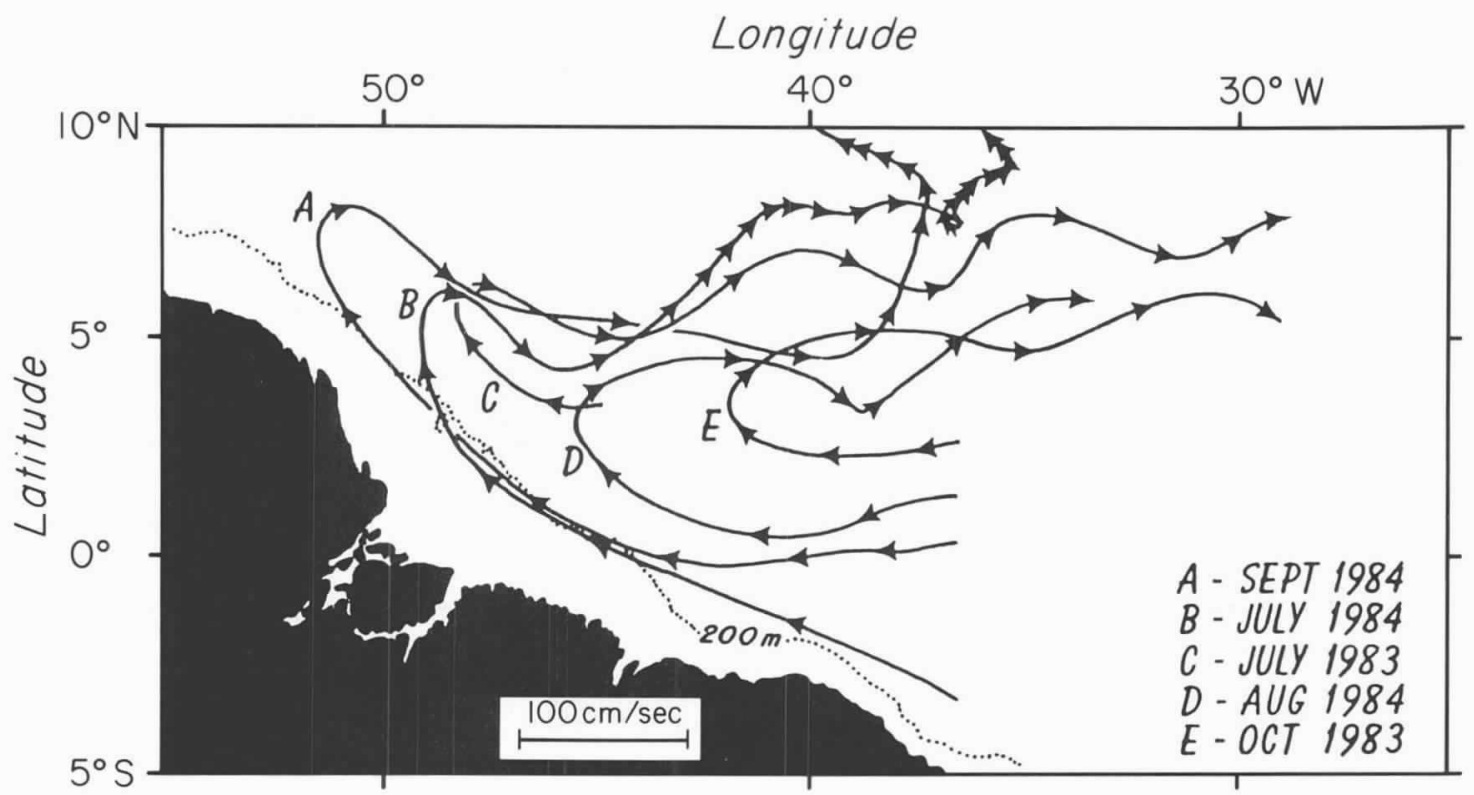

Fig. 1: Float tracks demonstrating the retroflection of the NBC (after Richardson and Reverdin, 1986). 
minimum across $8^{\circ} \mathrm{N}$. When the model NBC is continuous along the coast, northward heat flux is a maximum. Thus, the western tropical Atlantic Ocean appears to be a critical location for monitoring the net northward heat (and fresh-water) fluxes in the Atlantic basin. Several other numerical models have been applied to the region for somewhat different purposes (Schott and Böning, 1991; Thompson, McCreary, personal communications). All of these model results show an undercurrent flowing southward along the slope to join with either the equatorial undercurrent (EUC) or a subsurface branch of the NECC, depending on season. Although this flow has been detected in hydrographic sections, it has not been observed directly. Clearly, models will continue to play an essential role in estimating heat and mass transports and suggesting strategies for observing this complex region.

The observational and modeling studies of the western tropical Atlantic to date raise a host of important scientific questions concerning the dynamics of the various current components concentrated along the western boundary. In particular, it is unclear why the thermocline and subthermocline currents separate from the western boundary at different latitudes to feed the various zonal flows. Are separation latitudes dictated primarily by the structure of the wind-forced flow regime in the central basin or do local boundarycurrent dynamics prevail? What forces the subsurface currents? What is the dynamical role for the NW-SE orientation of the South American coastline?

Other dynamical questions concern the role of the western tropical Atlantic in the dynamics of the thermohaline circulation of the Atlantic region. In particular, do the western tropics have a significant dynamic role in controlling the intensity of the meridional overturning cell in the Atlantic basin? There are also key questions concerning the deep-circulation components. In particular, do deep recirculation gyres, like those observed south of the Gulf Stream, exist in this region? If so, what is the offshore transport of the deep western-boundary current? What is the relationship between the thermohaline and eddydriven transports? How is the deep eddy field related to the near-surface circulation field? What is the temporal variability of the deep circulation?

Many of these scientific issues are being addressed by WESTRAX.

\section{The WESTRAX Study}

One of the long-term goals of physical oceanographic research in the western tropical Atlantic is to estimate the cross-equatorial transport of water and heat. In order to detect long-term changes in the meridional mass and heat transport of the tropical Atlantic, a much better understanding of the seasonal variability in the current and property structure of the region must be obtained. Toward that end, an international group of scientists (Table 1) is cooperating in the context of WESTRAX to determine the first-order kinematics and dynamics of the flow in the western tropical Atlantic. During 1990 and 1991, the WESTRAX field program has obtained data that will be used to describe the annual cycle in the large-scale structure of the velocity and hydrographic properties over the full water column in the western tropical Atlantic Ocean between the equator and $15^{\circ} \mathrm{N}$. Subsequently, the field data and model results will be compared in order to better understand the physics of the regional circulation in the broader context of Atlantic-basin thermohaline circulation.

\section{Scientific Objectives}

The specific objectives of the WESTRAX studies are as follows:

1. to describe the annual evolution of the threedimensional velocity field for the NBC, Guiana current, and the western parts of the NECC, south equatorial current, and EUC;

2. to determine the seasonal changes in the transport connecting the different components of the upper-level current system in the western tropical Atlantic;

3. to measure the temporal changes in the structure and transport of the intermediate and deep western-boundary currents in the region;

4. to determine the basic physical mechanism controlling the evolution of the NBC retroflection and associated eddy dynamics in the region; and

5 . to estimate the proportion of the net meridional transport contained in the western boundary current system.

\section{Experimental Plan}

Observations. The WESTRAX observations include: ship surveys with Conductivity Temperature Depth and Oxygen probe $\left(\mathrm{CTD} / \mathrm{O}_{2}\right)$, Expendable Bathythermograph (XBT), and Acoustic Doppler Current Profiler (ADCP) measurements;

Table 1

WESTRAX activities and associated principle investigators.

NOAA/NSF Large-Scale Ship Surveys, Pegasus/Doppler Velocity, $\mathrm{CTD} / \mathrm{XBT} / \mathrm{O}_{2} /$ Nutrient-

W. Brown (UNH), E. Johns (NOAA), K. Leaman

(RSMAS), R. Molinari (NOAA),

D. Wilson (NOAA).

RSMAS Moored Currents-W. Johns, T. Lee

Kiel Modeling, Pegasus Velocity, CTD Ship Surveys,

Moored Currents-F. Shott

Lamont Moored Inverted Echo Sounders-E. Katz

ORSTOM Small-Scale Ship Surveys, Moored CurrentsC. Colin

Wood's Hole Oceanographic Institute Floats-

P. Richardson, W. Schmitz

Maryland Modeling-J. Carton

Nova Modeling-J. McCreary, P. Kundu, P. Lu

NOARL Modeling-D. Thompson. J. Kindle. H. Hurlburt goals . . to estimate

the cross-equatorial

transport of water and

heat. 
TROPICAL WESTERN ATLANTIC

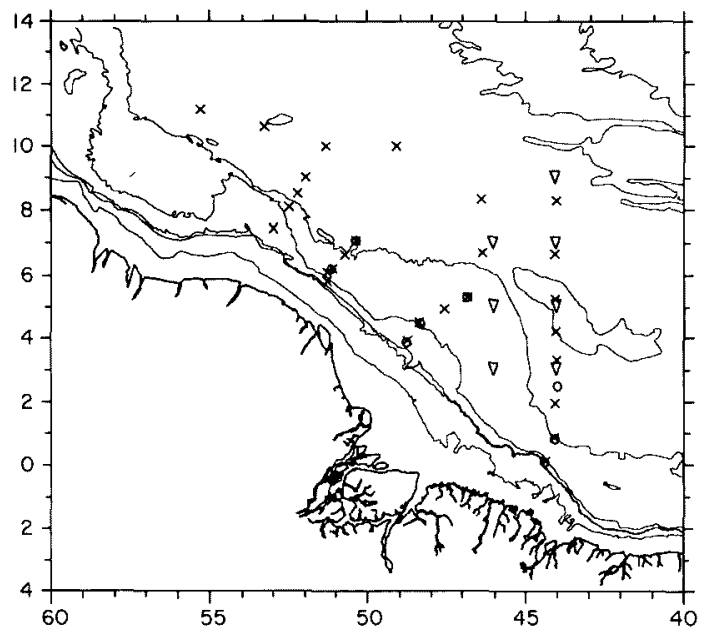

Fig. 2: The WESTRAX moored array. The Pegasus-profiling $(X)$, current-meter (open circles), and inverted-echo-sounder (inverted triangles) stations are indicated.

and moored arrays consisting of current meters, inverted echo sounders, and acoustic transponders for repeated shipboard Pegasus velocity profiling (Fig. 2). Deployments of deep floats and a few surface drifters augment the other observations. The 1990-1991 schedule of WESTRAX activities is presented in Fig. 3.

There were five large-scale shipboard surveys of Pegasus and Doppler absolute velocity and hydrography supported by NOAA and NSF (National Science Foundation) (Fig. 2). These surveys were timed to sample the regional current system during different phases in the annual cycle of the near-surface NBC. A comparison of the January 1990 and 1991 survey results will make possible the estimate of interannual changes in the system. The French at the Office de la Recherche Scientifique et Technique d'Outre-Mer (ORSTOM) conducted a series of Pegasus and CTD measure-

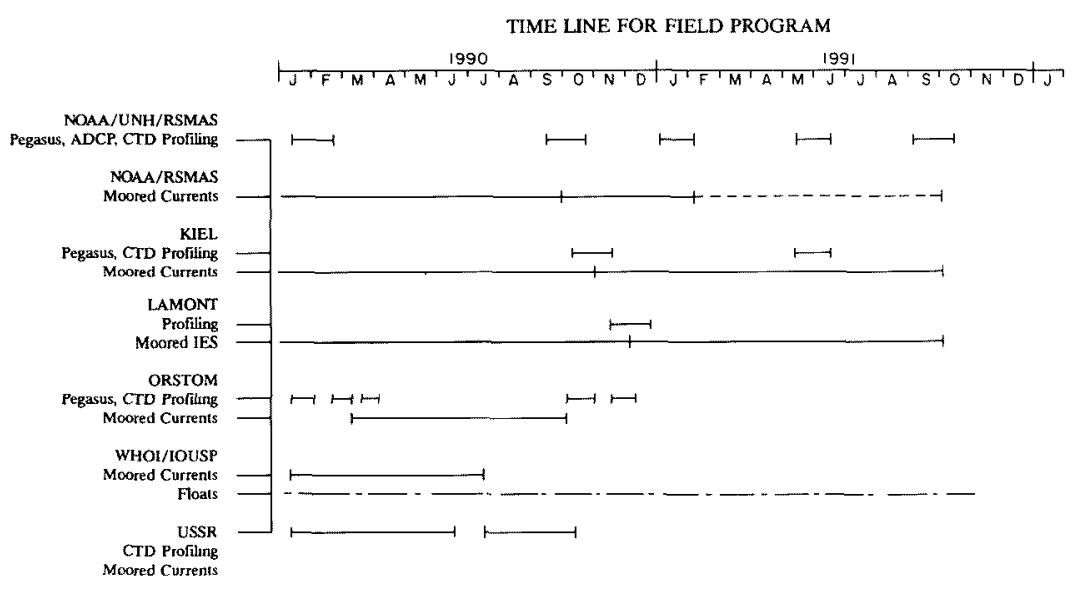

Fig. 3: The WESTRAX timetable of field-program activities. ments along a transect from the coast of French Guiana to the nominal center of the Demerara Eddy.

The elements of the moored array were located so as to monitor the variability of the NBC, equatorial, and deep western-boundary current systems at several key locations. The Kiel current-meter moorings spanned the NBC along $44^{\circ} \mathrm{W}$ near the equator (see Fig. 2). The University of Miami (RSMAS; Rosenstiel School of Marine and Atmospheric Sciences) moored current-meter array spanned the NBC at $\sim 5^{\circ} \mathrm{N}$ between the Amazon and Demerara Eddies. The short-term ORSTOM current-meter array spanned the NBC at $\sim 7^{\circ} \mathrm{N}$. The Lamont inverted echo sounders (IES) were used to monitor the dynamic height field and associated geostrophic transport associated with flow into and out of the NBC retroflection region.

In an effort to measure the cross-equatorial transport of subsurface water, Woods Hole Oceanographic Institute (WHOI) launched 44 Sofar floats and 4 Bobbers in early 1989 distributed at depths of $800,1,800$, and $3,500 \mathrm{~m}$. Most of the floats were deployed in the western boundary current at $\sim 6^{\circ} \mathrm{N}$ between French Guiana and Brazil, some along the equator, and some along $11^{\circ} \mathrm{N}$. A pair of surface drifters-deployed in the region of the NBC retroflection in November 1990-provided Lagrangian current information in the region until mid-February 1991.

Modeling. Nova University modelers are using a 2 $\frac{1}{2}$-layer model (a 3-layer model with an inert lowest layer) to study regional dynamics. The relatively simple model contains many of the essential dynamical processes believed to be important in the WESTRAX region: a subsurface layer for the development of undercurrents, nonlinearities that allow for unstable currents, a parameterization of upwelling and entrainment, and thermodynamics in both layers. The model is being forced with realistic winds, and the resulting solutions are being compared with observations. To investigate the fundamental dynamics, a variety of dynamically simpler solutions are being obtained and contrasted. Naval Oceanographic and Atmospheric Research Laboratory (NOARL) modelers are developing a hierarchy of primitiveequation layer models in both global and regional basins with resolutions varying from eddy-resolving to rather coarse grids. Of relevance to WESTRAX is their interest in understanding the dynamics responsible for the 26- and 50-day oscillations observed in the equatorial Atlantic (Johns et al., 1990). Kiel University modelers are comparing different solutions to a multilevel GCM with one another and with observations. University of Maryland modelers are conducting modeling and assimilation studies of the tropical Atlantic Ocean using primitive equation models to define the mechanisms controlling seasonal storage and transport of heat, momentum, and salt. 
Relation to other programs. WESTRAX benefits from other ongoing programs in the region. For example, the Tropical Ocean and Global Atmosphere Program (TOGA) supports some of the Lamont IES (E. Katz) and XBT ship-of-opportunity (R. Houghton) observations pertinent to WESTRAX objectives. The NSF-supported AmasSeds project (A Multidisciplinary Amazon Shelf SEDiment Study) in the region of the Amazon outflow includes a physical oceanographic component (R. Beardsley, WHOI; B. Castro, Instituto Oceanográfico, Universidade de São Paulo [IOUSP]) on the landward side of the WESTRAX region. Collaboration is also anticipated with the Soviets, who conducted three extensive hydrographic and current surveys of the region in 1990.

Although the observational phase of WESTRAX has ended, the WESTRAX Pegasus transponders should be useful through September 1992. The community is encouraged to take advantage of that opportunity to make further measurements, as well as to engage in other relevant collaborations with WESTRAX investigators.

\section{Acknowledgements}

In addition to the contributions of the authors, this description benefitted from discussions among the other participants in the January 1990 and February 1991 Miami WESTRAX workshops. W. Brown's effort was supported by the National Science Foundation under grant OCE 8912260 .

\section{References}

Atlantic Climate Change Working Group, 1990: Atlantic Climate Change Program Science Plan. NOAA Climate and Global Change Program, Spec. Rpt. No. 2, University Center for Atmospheric Research, 29 pp.
Broecker, W.S., D.M. Peteet and D. Rind, 1985: Does the ocean-atmosphere system have more than one stable mode of operation? Nature, 323, 301-304.

Bruce, J.G., 1990: Near equatorial eddies off South America. In: Report of the Second Brazil/U.S. Workshop on Physical Oceanography. W.S. Brown and F.O. Smith eds., University of New Hampshire, Durham, September 1989.

Bryden, H.L. and M.M. Hall, 1980: Heat transport by currents across $25^{\circ} \mathrm{N}$ latitude in the Atlantic Ocean. Science, 207, 884-886.

Csanady, G.T., 1985: A zero potential vorticity model of the North Brazilian Coastal Current. J. Marine Res., 43, 553-579.

Johns, E. and R. Molinari, 1989: Recent current and water mass observations along the western boundary of the tropical North Atlantic Ocean. EOS, Trans. $A G U, 70$ 360.

T.N. Lee, F.A. Schott, R.J. Zantopp and R.H. Evans, 1990: The North Brazil Current retroflection: Seasonal structure and eddy variability. J. Geophys. Res., 95, 22103-22120.

Metcalf, N.G. and M.C. Stalcup, 1967: Origins of the Atlantic equatorial undercurrent. J. Geophys. Res., 72, 49594975.

Muller-Karger, F.E., C.R. McClain and P.L. Richardson, 1988: The dispersal of the Amazon's water. Nature, 333, 5659.

Philander, S.G.H. and R.C. Pacanowski, 1986: The mass and heat budget in a model of the tropical Atlantic Ocean. J. Geophys. Res., 91, 212-220.

Richardson, P.L. and G. Reverdin, 1986: Seasonal cycle of velocity in the Atlantic NECC as measured by surface drifters, current meters and ship drifts. J. Geophys. Res., 92, 3691-3708

Schott, F.A. and C.W. Böning, 1991: The WOCE model in the western equatorial Atlantic: upper layer circulation. J. Geophys. Res., 96, 6993-7004.

Vonder Haar, T.H. and A.H. Oort, 1973: New estimate of annual poleward energy transport by Northern Hemisphere oceans. J. Phys. Oceanogr., 2, 169-172.

Weisberg, R.H. and T.Y. Tang, 1985: On the response of the equatorial thermocline in the Atlantic Ocean to the seasonally varying trade winds. J. Geophys. Res., 90 , 7117-7128. 